\title{
Refiguring self and identity through volunteer tourism*.
}

by Stephen Wearing and John Neil

Stephen Wearing, Senior Lecturer, School of Leisure, Sport and Tourism, University

of Technology, Sydney

(s.wearing@uts.edu.au)

John Neil, Research Officer and Tutor, School of Leisure, Sport and Tourism, University of Technology, Sydney

(s.wearing@uts.edu.au)

School of Leisure, Sport and Tourism

University of Technology Sydney

P.O. Box 222

Lindfield 2070

\begin{abstract}
$\underline{\text { Abstract }}$
What are the impacts of the travel experience on the tourists self and identity? Does volunteer travel provide the opportunity to seek identity in other ways? Interactionist and postcolonialist theories explored within the context of leisure and tourism studies may enable us to move beyond what has remained largely within the tradition of western thought: a predominance of travel to escape, establish identity and a sense of personal individuality in the face of anomic forces of a technological world. It seems timely to develop a self reflexive analysis of those practices assumed to be separate, such as an analysis of the self across cultures in the developed and developing world. We seek to achieve this using volunteer tourism as the focus, examining a dominant cultures' male view of destination communities and nature as 'other' in leisure activities. A greater recognition and incorporation of these in travel experiences allows us to not only enlarge our sense of individual self, but also benefit the communities in which we live and visit.
\end{abstract}

\footnotetext{
* An earlier version of this paper was presented at the International Sociology Conference, World 14th Congress on Sociology, Montreal, July 26 to August 11998
} 


\section{Refiguring self and identity through volunteer tourism}

\section{Introduction}

"I think 'tourists' has also turned into a very negative word, it is used in a negative sense, like 'that person is a tourist and that one's not'. There were visitors at the reserve who came for a short time, but they played by the local rules, they weren't noisy or throwing cigarettes butts around, they had a bit of respect for the place. They might not have been there very long, but they were still getting something out of it. I think the reason that 'tourist' gets a bad name is because they seem to walk around in a little bubble within this other culture and it's all bouncing off. They're acting and walking around as though they still haven't left anywhere. But some people come for a much shorter time, and they would walk through the reserve once, but they would do it in a way that you can see that they're interacting with it. I think some tourists only interact with each other, like the other members of the tour party and that's it. It doesn't go out into the environment or the community, it just stays between them. It's like they're coming in and feeding the animals and memories and taking them home to share with people back home, not to provide sharing between themselves and the community, which they can both remember. They're coming and taking and then going back home, like a competition." (Mic - volunteer tourist), (Wearing, 1998b: 33).

Tourism is essentially a modern western phenomenon, the analysis of which has evolved from pre-modernism through to post-modernism. It differs significantly from non-western and historical forms of travel, being closely related to the emergence of 
modernity with the concomitant emphasis on economic viability. The growth of tourism as a social phenomenon and the tourist industry as an economic enterprise has been dramatic during the last half of the twentieth century (WTO 1999, 1990; WTTC 1999, 1993). Indeed, tourism has become a major social and economic force in many countries and regions throughout the world (Weaver and Opperman, 2000). The profusion of tourist experiences that has resulted during the last twenty years has generated a variety of means of theorising, analysing and marketing tourism. Tourism theories and research have ranged from micro-social psychological explanations to macro-social explorations concerning the globalization of tourist venues, in part as a response to the increasing domination of the market by multi-national corporations and the increasing proliferation of international travellers. This has occurred in conjunction with increases in leisure time, disposable income and mobility, technological improvements in communication and transportation, demographic changes and a shift in the axis of personal identity from production to consumption (Veal and Lynch, 1996).

The approach in this paper recognises that there is a need to articulate a theory of value and meaning entirely dependent upon the space-time relations between the 'I' and the 'Other', while accepting the primacy of unique individual experience however avoiding subjectivism. This uniqueness of the self is precisely that condition in which the necessity of the other is born. As we travel with ourselves we see the 'other' as a world we are travelling though; but at some stage does that 'other' become a part of ourselves? This paper is then about that dialogue: interpersonality, boundaries, travel, self and nature. It focuses on the volunteer tourist, as they appear to best represent the type of tourism that allows us to examine this area. 
We begin with the self as it offers us something — a starting point — to link interactionist traditions with the poststructuralist/postmodern inheritance that, some would have us believe, would posit a deconstructed subjectivity in which self and subjectivity are exposed as a socially constructed fiction. Concepts such as death of the author and death of the subject signify a turn away from the celebration of individual worlds and subjectivities, and from personal power for the sake of a better appreciation of the nature of social power and the structures of domination, exploitation, repression, and the text (Game, 1991; Jagtenberg and Mckie, 1997:128)

In accounting for tourism as a global phenomenon, much of the initial sociological work was concerned with the individual tourist and the part that holidays play in establishing identity and a sense of self. This self was predominantly posited as a universal and tourism, like leisure, was seen in a dialectical relationship with the ‘workaday world’. Cohen and Taylor (1976), for example, drew on Goffman’s (1974) concern with the presentation of self in everyday life, to argue that holidays are culturally sanctioned escape routes for Western travellers. One of the problems for the modern traveller, in this view, is to establish identity and a sense of personal individuality in the face of the anomic forces of a technological world. Holidays provide a free area, a mental and physical escape from the immediacy of the multiplicity of impinging pressures in technological society. Thus, holidays provide scope for the nurture and cultivation of human identity; as Cohen and Taylor argue, overseas holidays are structurally similar to leisure because one of their chief purposes is identity establishment and the cultivation of one's self consciousness. The tourist, they claim, uses all aspects of the holiday for the manipulation of well-being. 
However, in the tourist literature, these arguments became diverted into a debate about the authenticity or otherwise of this experience ( $c f$. MacCannell, 1976; Cohen, 1988), serving to focus attention on the attractions of the tourist destination. Such a shift objectified the destination as place - a specific geographical site presented to the tourist for their gaze (Urry, 1990). Thus the manner of presentation became all important and its authenticity or otherwise the focus of analysis: 'I categorised objects of the gaze in terms of romantic/collective, historical/modern, and authentic/unauthentic', says Urry (1990:135). The tourists became synonymous with the Baudelarian flaneur: 'the strolling flaneur was a forerunner of the twentieth century tourist' (Urry, 1990:138). This flaneur was generally perceived as escaping from the workaday world for an 'ephemeral', 'fugitive' and 'contingent' leisure experience (cf. Rojek, 1993: 216).

In such an analysis tourism becomes a mass phenomenon, predicated on ontological universal categories with sharply dichotomous conceptions utilised to account for the dynamic processes, interrelations and the inherent divergences of tourism experiences. However, as Cohen acknowledges, authenticity does not have an 'objective quality', but is attributed by moderns to the world 'out there', and thus is a socially constructed concept with a connotation that is not given but 'negotiable' (Cohen, 1988). 
Therefore, the theorisation of tourism, like that of leisure ${ }^{1}$, needs to recognise the interrelation of time, site and the activities provided for at the tourist destination. It must also require a fundamental focus on the individual subjective experience itself in providing for the significance of the tourist experience. This, while not being divorced from its sociological contextualisation, allows for the elaboration upon the role of the individual tourist self in the active construction of the 'tourist experience'. This locating of the centrality of experience is thus relational in respect to the individual, the individual's social groups, their travel experience and the elements that are required to sustain that experience. This paper takes on these constructs in attempting to provide an analysis of the phenomenon of the volunteer tourism experience ${ }^{2}$.

Analyses of tourist destinations as image in tourist advertising and tourist research ( $c f$. Bramwell and Rawding, 1996; Cohen, 1995; Gartner, 1993; Echtner and Ritchie, 1991; Telisman-Kosuta, 1989; Dilley, 1986) assumes that each individual's experience of the tourist destination will be similar. There is however, a significant body of research that indicates that such a conceptualisation is, in fact, counterproductive ( $c f$. Dann, 1995; Rowe and Stevenson, 1994). Thus, this paper further seeks to explore the possibility of a more useful conceptualisation of the tourist: that is, as someone who is influenced by the subjective meanings through which they are affected, constructed in interaction with the space and people that form

\footnotetext{
${ }^{1}$ See for example Wearing and Wearing (1988) for a definition of leisure as experience. The term is used here to encompass tourist experiences which are considered to be a sub-group of leisure experience, leisure theory being the underlying theoretical contributor to the sociological analysis of tourism ( $c f$. Cohen, 1995).

2 The generic term 'volunteer tourism' applies to those tourists who, for various reasons, volunteer in an organized way to undertake holidays that might involve the aiding or alleviating the material poverty of some groups in society, the restoration of certain environments, or research into aspects of society or environment (Wearing, 2001).
} 
the destination site. It is the experience of the interaction in this specific space that affects the socially constructed self who travels between specifically bounded spatiotemporal co-ordinates.This is the core of the volunteer tourist's experience. Therefore, the volunteer tourist as a wanderer seeking simply to repudiate established tourism experiences (Cohen, 1995: 13) is critiqued as still failing to incorporate or recognise elements that may provide for an understanding of the experience. In drawing upon a wide range of theory concerning agency, subjective meanings, subjectivities and the self — specifically in relation to volunteer tourism and a concomitant emphasis on interpersonal relationships - the conceptualisation of the tourist destination as an interactive space — provisionally indicates a number of elements that may contribute to a shift in the way that the tourist experience is analysed. The shift away from the tourist experience as simply that of an itinerant 'gazer' towards an interacting agent within a specific spatio-temporal site and a series of processually exchangeable interactions, facilitates the movement towards a consideration of the differential elements that contribute towards the totality of the tourist experience. This leads to an exploration of the idea of the volunteer tourist who moves beyond the 'gazer' and to become an 'interactive' contributor to the site and experience.

Tourism as experience - involving complex and often subtle interactions between the tourist, the site and the host community - presents problems and limitations for volunteer tourism if analyses are predicated on the conceptualisation of the tourist as 'wanderer', 'gazer' and 'escaper' (as is common in the literature on both mass and alternative tourism). As the tour group, the host community and the natural ( . . continued) 
environment, to varying degrees, are all components of any tourist experience, there is a need to move beyond these boundaries towards a more analytically flexible conceptualisation. This entails a fundamental re-evaluation through the challenging of existing notions, bringing into focus often overlooked convergences and processual elements (Grosz, 1989; 1995). This allows for the exploration of the assumptions implicit in the 'tourist gaze', the tourist 'destination', the marketing 'image', the 'visit', suggesting other modes of analysis that may better account for the significant range and diversity of tourist experiences.

\section{Tourism, volunteer tourism and identity}

"So Santa Elena in particular, I think that's why it stuck in my mind so much because, it seemed to me to represent what could be achieved and what communities can be, and what individual people can do for themselves. I think it was a booster in faith and a hope in humanity. So personally it committed me to what I was doing, it solidified values that I was just starting to change. You are always reassessing your values and effects and morals and what are you actually working for, and what they mean” (Ros - volunteer tourist), (Wearing 1998a: 193).

Alternative tourism in which we situate volunteer tourism is now being seriously considered as a significant area of tourism experience (Cohen, 1987; 1995; Holden, 1984). However, a number of authors (Butler, 1992; Cohen, 1995) have attempted to incorporate it into the analysis of 'mass tourism' thus subordinating it to mainstream tourism research. Questions thus arise as to the feasibility of volunteer tourism being 
analysed in terms of a separate construct or different paradigm. Figure one attempts to provide a conceptual schema that fits volunteer tourism into the existing models of tourism and leisure.

\section{Insert figure one here}

The popularity of specific forms of alternative tourism, such as ecotourism ${ }^{3}$ (a relatively new term in the world's vocabulary) and here the relational volunteer tourism, has increased significantly (Wearing, 2001). The generic term ‘volunteer tourism’ applies to those tourists who, for various reasons, volunteer in an organized way to undertake holidays that might involve the aiding or alleviating the material poverty of some groups in society, the restoration of certain environments, or research into aspects of society or environment (Wearing, 2001). In presenting the schema above, it is taken in this context to act as a subset of alternative tourism, however part of the wider ecotourism construct. While the terms are not immediately synonymous, for the purposes of this discussion their key tenets are similar in that ecotourism brings with it a desire to discover the relationship that travel though nature has with ideas of the 'self' and 'other' and as a result impacts on identity. The body of literature concerning

\footnotetext{
${ }^{3}$ Boo (1990:10) provides the most cited definition to date: 'We may define ecological tourism or ecotourism as that tourism that involves travelling to relatively undisturbed or uncontaminated natural areas with the specific object of studying, admiring and enjoying the scenery and its wild plants and animals, as well as any existing cultural aspects (both past and present) found in these areas. Ecological tourism implies a scientific, aesthetic or philosophical approach, although ecological tourist is not required to be a professional scientist, artist or philosopher. The main point is that the person that practices ecotourism has the opportunity of immersing him or herself in nature in a way that most people cannot enjoy in their routine, urban existences ...'. As there is no strict consensus on a specific definition of ecotourism, numerous examples abound. Fir example, The International Ecotourism Society (2001) defines ecotourism as 'responsible travel that conserves natural environments and sustains the well-being of local people’.
} 
'alternative tourism' and touristic practices themselves is used in the exploration of how volunteer tourism experiences may relate to what are considered as mainstream or conventional tourism experiences. Through the identification of the specific elements of a volunteer tourism experience it will be suggested that such a form of tourism practice can be considered, within a framework provisionally moved towards in what follows, as a form of alternative tourism experience, and more precisely, a volunteer tourism experience. It is in the spirit of dialogue presented this paper, Tom Jagtenberg and David Mckie in Eco-Impacts and the Greening of Modernity (1997) have already initiated a cartographic project that in many ways connects with our own. In 'exploring the exclusion of self-concepts from social theory', Jagtenberg and Mckie’s cartographic method incorporates a number of convergent perspectives 'from a postmodernized interactionism, through deep ecology, to the coming of the cyborgs...[in order to investigate] how a postmodernized interactionism can contribute to an understanding of processes of ecological identification. Our starting point is the observation that the critical importance of ecological location in the conceptualisation of self and identity has not been addressed in social, cultural, and communication theory’ (Jagtenberg and Mckie, 1997: 121).

To date, sociological analyses of tourism have developed two predominant themes concerning the self of the traveller. On the one hand there has been an emphasis on tourism as a means of escape from the everyday, even if such escape is temporary. On the other, travel has been constructed as a means of self-development, a way to broaden the mind, experience the new and different and to come away in some way enriched. One adopts a pessimistic view, suggesting there is no escape (e.g. Cohen and Taylor, 1976; Rojek, 1993) and the other moves to an optimistic outlook in which 
substantial benefits accrue from the tourist experience (e.g. Brown, 1992; Pearce, 1984). Others, such as MacCannell (1992) attempt to balance the two views. MacCannell, for example, sees the touristic movement of peoples both to and from the western world as an opportunity to form hybrid cultures, a precondition for inventing and creating subjectivities that resist cultural constraints. He claims that the neo-nomads of tourism in the postmodern era cross cultural boundaries not as invaders, but as imaginative travellers who benefit from displaced self-understanding and the freedom to go beyond the limits that frontiers present. The 'true heroes' of tourism, he claims, are those who know that 'their future will be made of dialogue with their fellow travellers and those they meet along the way’ (1992: 4).

Conversely however, modern travel, particularly in its increasingly corporatised form, 'is an overturned nomadic consciousness in which the ultimate goal of travel is to set up sedentary housekeeping in the entire world, to displace the local peoples, or at least to subordinate them in the enterprise, to make them the 'household' staff of global capitalists' (MacCannell, 1992: 5). This form of ingesting the 'other' into the self - and subsequently eliminating it - is termed contemporary cannibalism: where the tourist consumes and destroys the culture of the host peoples in developing countries. Far from enlarging the self MacCannell sees this form of tourism as supplying the energy for 'autoeroticism, narcissism, economic conservatism, egoism, and absolute group unity or fascism' (1992: 66). The tourist self, in this view, remains rigid or static and turned in on her/himself - shrinking, rather than expanding, or, in Craib’s (1998) view, closing down psychic space where the self of the host person is devalued and diminished. 
The meanings assigning to why people travel are being questioned here, i.e. travel to escape (cf. Rojek, 1993; MacCannell, 1992; Urry, 1990) or travel for selfdevelopment. Rather than dichotomising these they can be used to build on each other to develop more fully the explanation surrounding the traveller. The tourism field is about to undergo radical shifts in conceptions of how it theorises the traveller who has come from a very diverse group of people. The race, gender, age, etc (cf. Richter, 1995) variables have come into play. No longer can we assume a benign understanding of the operations of social power across cultures, but we need to understand and incorporate it. The traveller is knowledgeable of their impacts, however volunteer travel is underpinned by an ethic of care and moral concern for the host country. What this assumed 'goodness' does is often obscure the very real workings of power in the way people's lives and bodies are managed. Leisure and tourism is now considered as playing an important role in terms of the desire to improve people's quality of life.

Unfortunately, current understandings of tourism tend to assume that a notion of freedom of choice lies with the individual. The way travel options have been constructed reveals something of the way marketeers construct images of destinations (cf. Wearing and Wearing, 1996a). This is by no means a deliberate ploy, but part of the operationalisation of power through tourism management where the experiences of leisure a person has works towards constituting their subjectivity and understanding of choice. For example, modern day manifestations of mass tourism, typically characterised by air-conditioned coaches and rigorous schedules, are in some ways disturbing. The assumptions underlying such practices are that international tourists are a homogenous group of travellers whose tourism experience 
is a collective means of occupying time that can be supervised, managed and ordered according to the desires of the profit-motivated operator. If an individual has spent much of their life being managed and controlled in their tourism experiences then what opportunities are available to them to know otherwise? Tourism is only then contributing to a normalising effect that, in Foucault's (1983) terms, contributes to the production of a 'disabled subjectivity'. Thus the spiral emerges where the person's limited knowledge leads to operators that are ignorant of tourist needs and subsequently providing constructed choices based purely on profit motives.

There has been increasing moves towards more specialised tourism practices in the recognition of niche markets, and with such moves must come theoretical understanding and development. If postmodern thought has contributed nothing more it has enabled us to examine individual peoples difference and the impacts of their own experience on the self as opposed to macro-indifferent reductionism based on hegemonic theoretical approaches. Reconceptualising interactionist theory around the ideas of postmodernism in terms of tourism travel, with contributions from post-colonial theory, allows examination of the reconfiguration of interactionist theory to enable it to suggest how it might effect identity formation through travel (the importance of leisure to identity formation has been put forward by Clark and Critcher, 1985; Rojek, 1985; Kelly, 1983; Wearing and Wearing, 1992). Roberts (1983:62) states that 'adolescent leisure is usually a scene where conventional gender identities plus sexual tasks and skills are reproduced, not rejected'. However, feminist analyses suggest that leisure can be both an area for the subordination and domination of women and an area of resistance to dominant ideologies and discourses (Wearing and Wearing, 1988; Wearing and Wearing, 1992). 
Questions are raised within this framework as to the influence of travel on the identity formation of the volunteer tourist. Given that the volunteer tourist is often young (Wearing, 1998b), travel opportunities suitable for youth that enable them to experience a multiplicity of subjectivities about themselves (to reconfigure themselves) provide different models of identity formation (see quotes below). The question is: can we create theoretical constructs that enable an understanding of this in any comprehensive way? While many white males have role models and a culture that provides them with individual competitive pursuits which at least give them a perception of identity, many other males and females lack such a culture and are thus deprived of the opportunity to develop identity through leisure activities to the same extent (cf. Wearing, Wearing and Kelly, 1994), these individuals sometimes look to volunteer tourism to seek out new identities.

\begin{tabular}{|l|l|}
\hline “...building my own character, confidence & “...there was that personal development \\
and self-development (Jen). & aspect” (Lil). \\
“I like to push myself to see what my & "I guess to get a sense of achievement at \\
limits are” (Ann). & what I was doing (Ros). \\
“...it was a bit of a growth thing.” (Meg). & “...more independent and self-assured \\
& and sure about who I am” (Sue). \\
\hline
\end{tabular}

(Wearing, 1998b: 141) 


\section{Interactionism and theoretical traditions}

The development of a deconstructive analysis of the presuppositions that underpin knowledge practices in the theory and practice of tourism travel is therefore proposed $^{4}$. This analysis is primarily through the conceptualisation of self, particularly in the interaction across cultures and focussing on nature and/or community projects, such as those associated with as ecotourism or volunteer tourism. The often explicit and implicit epistemelogical assumptions that have long pervaded this field have not fully been analysed in relation to their situation within the operations of power and resistance in knowledge practices, however in recent years attempts have been made to address this (cf. Hollinshead 2000, 1999a, 1999b). Such questions draw on the post Hegelian tradition in contemporary philosophy that posits knowledge as desire, in a formulation that disrupts the now often rhetorical deconstruction of Cartesian rationality premised on the mind-body dualism. The epistemological heritage of leisure and tourism studies (cf. Cohen, 1995) must be placed within the broader history of western philosophy and logocentrism. For leisure and tourism theory has invoked the classical connections between leisure and rational contemplation in a desire to establish a sense of origins. The desire for origins in this system of metaphysics, of truth, certainty and reason has been the focus of much

\footnotetext{
4 The theoretical traditions that bear historically on discourse about self and subjectivity are vast. But the placement of interactionist and phenomenological notions of self and identity in the context of poststructurallsm and postmodernism may seem to further problematise what seems quite a chasm of theoretical divide between the decentered, fragmented, and multiple selves and subjectivities; postulated in the latter against the former seeming adherence to an Identity logic that historically has privileged a white, patriarchal, Western view. But there Is a theoretical common ground: Interactionism develops a process model of the self in which communication Is a major axis. These processes of the self are, furthermore, not a priori anathema to social structure, difference, conflict, or ecology—and indeed, it is with these directions that interactionists and cultural theorists may find a rare piece of common ground.
} 
deconstructive analysis as to the hierarchical structure of oppositions in western knowledge, but as yet there has been little engagement in leisure and tourism studies with these post-structuralist ideas.

Experiences 'in the field' ( $c f$. Wearing, 1998b) have lead us into the major concern of how social theory, and specifically interactionist theory, is able to conceptualise the nexus of relations inhering in the cross-cultural relational exchange between 'selves' through tourism experiences. The traditional primacy of a conceptual division between theory and practice has held sway in tourism: the contemplation of the world as it exists to be known "out there”. However, deconstructive sociologists such as Anne Game (1991) have shown that theory has been understood as a reflective knowledge, a mirror of the real, a representation that denies its own desire and mediation. Tourism theory has remained within this tradition that relies on a Cartesian rationality, a speculative knowing that is exclusive of the other (i.e. culture) and disregards new ways of knowing. Paradoxically we end up with knowledge of tourism that excludes an ability to be inclusive of other cultures and nature. Thus an understanding of the self in travel and its representation arises through the desire to hold still the flux of meaning in order to master and know it. The organisation of leisure, and by association tourism theory, has overwhelmingly been structured by the desire for knowledge as stable truth and reflection in the asking of questions such as “what is a tourism experience?”. Contemporary theory has moved questions about meaning into a different order of analysis with particular reference to writing the body, deconstructing binary oppositions and decolonising truths. By engaging with this growing body of writing we could approach the study of tourism and its effects ( . . continued) 
on identity through a more open desire by asking "how does tourism mean?" in relation to the social. Tourism, as is its theorisation, is an embodied practice.

Refiguring leisure and tourism theory, particularly through interactionist theory, as an embodied writing practice breaks with the way in which knowledge of leisure and tourism has been constituted in both functionalist or neo-Marxist conventions as a self present phenomenon, reducible to class analysis or to a work-leisure binary that has particular phallocentric implications (cf. Wearing and Wearing 1996b). The embodied specificity of everyday tourism experiences, the contradictions and productive nature of pleasure are suppressed in totalising claims in knowledge that desires closure, certainty and singular truth. Tourism as a postmodern practice is one modality of many, often contradictory, social sites of reference groups, texts, cultural practices and discourses. It is a social field imbricated and implicated by heterogeneous symbolic exchanges across fields as diverse as psychoanalysis, art, film, and literature, all stitched into a mesh of the popular. It is amongst and across this field that the self traverses in its own idiosyncratic cartography.

The contribution of interactionism in the theoretical 'post' as an embodied theoretical practice is an important contribution towards mapping such a heterogeneous cartography. Classical interactionism's contribution is well noted in the movement away from the modern paradigm of subjective consciousness. It is placed firmly within a monadic, self reflexive and autonomous individual locus; in a movement increasingly directed towards the recognition of the social imbededness of the subject and the mediation of self within and between diverse and relative symbolic fields (the field determined by the system of relations constituted between a field of others - significant others, generalized others, and 
reference groups). The individual is an active one in the construction and reception of society that it internalises, transmuted into personal space and reproduced through social interaction. For Berger and Luckmann (1981), it is the self that is in dialectic movement, with all of its Hegelian overtones, whereby the self and society dynamic dialecticises this as a dialectic process mediated by the self.

Interactionism placed society and self as copresent realities. The self was foundational, conversational in intent, and the nodal point of a dialectic between an I and a me representing the ongoing construction of self in a social space. Self is in society and society is in the self. But in an world of increasing mediation in the interface between the self and society; the proliferation of discourses, processes of globalisation; the rise of the amorphous corporate internationals; regional and global multiculturalism; collapsing political and symbolic spaces; the rapid compression of space and time; and the potency of the simulacra, identity becomes increasingly problematic, almost to the point of becoming a subjective redundancy. It is in such a context that interactionist theorisation is squarely placed, a heterogeneous social field of multiplicity, flux, mobility, and the liminal rather than its historical roots in functional and routine mediation with a formative and 'solid' self. The explosion of identities, identarian politics of selves: core selves, male selves, female selves, dream selves, transcendent selves, ecological selves, and so on, are all part of the self (cf. Wearing 1998a).

Questions of using interactionism in analysing youth volunteer tourism experiences present an interesting conceptual problem: can interactionism deal with the idea of multiple subjectivities that involve travel across culture? Where are the boundaries between Mead's 'I' and 'me' when the insights of poststructuralism have challenged 
the very core distinction, the very object/subject distinction between the self and the other? The multiple, contradictory and contestory field of shifting identities, and the very challenge to the concept of identity inhereing in the contest/conquests of the other, places the discrete categorisation and delimitation of "I”, "me” and other.

Wearing (1998a) suggests that the positioning of the multiplicitious self across culture is a rewriting of the innante desire, in that is presently concerning movement, fluidity, openess and transformation. The "I" becomes a real, material body as well as a textual fiction; Iriagary's poetics of knowledge and metaphoric body undoes the literal-figural split: both at once she desires for the feminine, 'a possibility of unhindered movement, of peaceful immobility without the risk of imprisonment' (1993:12). The "I" can be seen as a profoundly embodied metaphor whose mutliplicity could be placed within contemporary writing as movement, in between, a temporality and spatiality of meaning that works through difference and deferral, and connects with identity. The meaning in an instance of identity-tourism is relational, a movement between the self and other, real and fantasy, literal and metaphoric that questions the separateness of each of those terms. It is this movement that is of the order of desire, to know the other, to experience the world and create meaning; tourism in this sense is the practice of desire or in perhaps more specifically the realm of the "I" as fixed to the desire of the "Me" and movement of meaning and understanding in interactionism (Wearing and Wearing 1999).

There is a paradox in construction of the "I" in interactionism, or more precisely a contradiction in the original theorising that assumes the body as a passive carrier of meaning and object of rational discourse with the "I" as fixed and unchanging. 
Contemporary theory takes the body not as a natural given but as the cultural product (Grosz, 1994; Butler, 1993). Tourism when theorised in interactionism in this sense is a significant practice of everyday life through which the body is produced as an effect of such materialisation processes. As an object of inquiry the "I" in the interactionist view of tourism requires thinking as to its relation to theory, the production of knowledge, or the body of the theorist. The movement of the "I" through culture in travel is suppressed through representational theory; this desire for mastery in knowledge also operates through the repression of passion. In developing a knowledge practice or writing of tourism experience principled on movement, pleasure and bodily sensuality is to argue for a passionate conception of knowledge-theory. Drawing on Irigaray's re-reading of Descartes first passion of 'wonder' we argue that there needs to be something of the experience of wonder found in tourism that inscribes theoretical practice (cf. Wearing, 1998a, Wearing and Wearing, 1999).

Irigaray takes wonder as the motivating force behind mobility in knowledge; in other words wonder is a different desire, to know the self and other-world in relation, through the body-senses (1993: 72). As the first passion, wonder is more than a passive conception of knowledge, rather it is the experience of knowing the world in its infinite flux and changeability - its otherness as respected rather than mastered in desire for singularity and stability. The application of this idea to Mead's "I” gives us an "I" that involves a passionate knowing of the world rather than a detached, disembodied and objective view. As such, tourism is the everyday practice that affects the world, and through which, we are affected as moving, becoming subjects. Bringing the body back into the play of theory we move tourism into a different 
economy of knowledge, one concerned with the desire to know as a passionate engagement with the world and an understanding of the body and the senses as central in the production of meaning in everyday life. In the phenomenological tradition of Merleau-Ponty and the early sociological work of Simmel, there are many opportunities to read this writing on bodily knowing with more contemporary textual analysis to refigure theoretical practices in leisure studies. Hence tourism and the theorising of it presents an ideal opportunity to reexamine aspects of interactionist theory (cf. Wearing, 1998a).

These theoretical concerns lead us directly to the refiguring of the ideas of interactionism. For too long this important micro social theory has remained stagnant to the extent that it is has largely been (in the last decade) a neglected domain of academic consideration. In terms of developing its direction within the postmodern era it needs to take on 'passionate' knowledge practices principled on the body and movement. Replacing the "I” in Mead’s idea with a multiple subjectivity gives us an avenue and a way in which we can move beyond a static model of interactionism that simply analyses theory and practice through the imparting of information in a dispassionate way (Wearing and Wearing, 1999).

The removal of the dichotomy of the "I" and "Me" removes the need to allow a continued process that crucially mediates between theory and practice, in that the self can be engaged with otherness across culture without the stagnant "I", and tourism becomes a passionate practice involving or moving towards interactions that excite the critical imagination. Uniting theory and everyday tourism experience is one such knowledge practice that brings together a self reflexive understanding of the practices 
of power and desire. What is needed are multiple ways of seeing the movement of the tourist across culture that allows for reflexive thinking in terms of the desire and power relations in knowledge, as the above examples illustrate. The "I" is no longer an observer - it exchanges and interacts with the "Me" who can still remain a crucial mediator of knowledge and meaning, but no longer a controller of it. The dispassionate "I" can no longer avoid being absent from the site of productive power relations, it now becomes a part of the engaging passions and creative innovations held out to be solely in the sphere of the "Me". Thus the dichotomy of the "I" and the "Me" in the self become more interactive, allowing a more reflexive self in tourism and a refiguring of interactionism (Wearing and Wearing, 1999).

This is illustrated somewhat by postcolonialist feminist theory which draws attention to cultures in which the western notion of an individualized self does not exist - 'self' and 'other' are interchangeable. Wearing (1998a) draws on poststructuralist feminists such as Lloyd (1989) and Grosz (1989), suggesting they have challenged and deconstructed many of the binary oppositions beloved of male post-enlightenment rationality. They have sought, for example, to eliminate the inferiorization of terms such as 'feminine' when set in opposition to 'masculine', body in opposition to mind, nature to culture, intuition to rationality. Ideas from this strand of feminist poststructuralism may allow us also to deconstruct the self/other dichotomy which has, to date, formed a foundation stone for the construction of leisure and tourism theory. In this dichotomous hierarchy 'self' is consistently valued over 'other' and leisure is repeatedly presented as contributing to the self in a distinctive way. Boundaries around the self serve to distance care and concern for others in this view of leisure. In the leisure literature the terms 'self-expression', 'self-improvement', 
'self-determination' and 'self-enhancement' abound. The implication has been that leisure is a unique sphere of life where the self can be nurtured and expressed and can grow in some way. This aspect of leisure may well apply to leisure activities in which competition and winning add to a sense of self-worth and status, such as the male dominated arena of competitive sport. It is proposed here, however, that in travel the 'other' has always played a vital part in a sense of self, but has failed to be acknowledged in the commodified world of travel and the developing area of tourism theory. These ideas can be applied to the area of volunteer tourism, specifically to the travelling self and its relation to communities and nature as "other”.

\section{The volunteer's self and nature}

Much of international volunteer tourism is based around a desire to assist in the conservation of nature (Wearing,. 1998b). Here the reasons and relationships the self can form with nature through a volunteer tourism experience are theorised. Within conceptualising the idea of nature, it is found that the classic dichotomy in the way individuals construct nature - through a primarily anthropocentric view (human centred; or ecocentric - equal value to all) - they are separated by a chasm created by differences rooted in religion, beliefs and behaviour. Anthropocentrism assumes that humans are the most important part of the ecosystem, and ecosystem function is sustained primarily for their benefit. Nature is a 'utility' and of 'value' because it is of use to human beings, if only as a place for camping and recreation (e.g. Hummel 1987). 
We can identify the ecocentric approaches, where the ecological well-being of the whole planet is emphasised regardless of the direct benefits of the human population inhabiting it (Rolston, 1992; Nash, 1989; Pepper, 1984; Godfrey-Smith, 1980; Leopold, 1949). Employing ecocentrism to prolong the integrity of natural ecosystems would be in sharp conflict with surrounding uses and the overpowering Western utilitarian ideology. Ecocentrism is not a policy that can be applied with officiousness, nor is it politically palpable - it is a philosophy that requires a deep thought process and a change in our exploitive attitude towards nature as a whole. If we apply the ideas of ecocentrism to travel we can start to formulate the merging of the treatment of nature as "other" to its incorporation into the self. In the final analysis of ecotourism we must bring the poles of ecocentrism and anthropocentrism to a junction which is about human's acceptance of the self/other dichotomy as invalid for this form of travel. The idea of travelling to incorporate nature into the self becomes prevalent and thus needs to be analysed ${ }^{5}$.

Arne Naess and George Sessions (in Devall, 1988) extend and frame Leopold's theme of holism into a reliable manifesto called 'the principles of deep ecology'. They believed that well-being and flourishing of human and non-human life on earth have value in themselves (intrinsic, inherent worth). These values are independent of the

\footnotetext{
5 Theoretical debates on the environment have been structured into three currents that are distinct from one another with respect to the seminal question: that of the relationship between/self and nature. The first is based on the idea that, by protecting nature, the self is still and foremost protecting itself. The environment is endowed with no intrinsic value here. Rather this scenario stems from an awareness that by destroying the milieu that surrounds him, man may be endangering his own existence. Thus nature is taken only indirectly into consideration and based on a position that may be classified anthropocentrist. This philosophy has also been classified as 'shallow' or 'environmentalist' ecology (Nash, 1989). The second current takes a step in the direction of attributing moral significance to certain nonhuman beings. It is the basis of the animal liberation movement, all beings capable of feeling pleasure and pain must be considered legal subjects and treated as such. The anthropocentrist point of view is thus discredited within this framework, since animal are included, by the same token as men, within the sphere of moral consideration (Nash, 1989). The third tendency is to say that nature in and of itself has rights. This philosophy is termed 'deep ecology' - which is 'ecocentric' meaning earth centred (Nash, 1989).
} 
usefulness of the non human world for human purposes. This leads us to believe that in travel we are able to develop the self and incorporate a belief in the self and nature becoming one. This has been expressed by Ceballos-Lascurain (n.d.: 1) in his original definition of ecotourism:

"This person will eventually acquire a consciousness and knowledge of the natural environment together with its cultural aspects, that will convert him (sic) into somebody keenly involved in conservation issues."

The above quote moves us to believe that travel can help develop the self/other ideal to one which opposes the paradigms that dominate Western society - the Judeo-Christian tradition - because it places the spirit and its law above nature; the technical concept of science that triumphed in Europe beginning in the seventeenth century with Bacon and Descartes, for it reduces the universe to a warehouse of objects to serve man; and the entire industrialist world, which gives priority to the economy over all other considerations (Holland, 1996). With certain authors such as Rolston (1992) and Nash (1989), we wish to inscribe the recognition of the rights of nature within the logic of democratic societies. We see volunteer tourism as a means of achieving this, of enabling the western traveller to move nature from a commodified product to become an inclusive part of the self through the volunteer travel experience.

If tourists remain within the traditional theoretical ideas that focus on tourism as a commodity, this leaves us with an inability to conceive pleasure except as being in some way connected with buying, travelling and spending. The purchasing of a travel 
package is never directly associated with that destruction of cultures through western tourist contact, the extraction of oil for jet travel, or the misuse of land for tourist accommodation. The invisible patina on the trip was its value, not its contribution to self-development, nature or an indigenous community. As Bookchin observes, 'the exploitation of nature is closely linked to human exploitation' (1982: 23). We can now understand Leopold's brevity of thought when he said 'we shall never achieve harmony with land any more than we shall achieve justice or liberty for people' (Leopold, 1949). He further noted that it 'has required nineteen centuries to define decent man-to-man conduct and the process is only half done; it may take as long to evolve a code of decency for man-to-land conduct' (in Nash, 1989).

Still, given the widespread appeal which nature seems to have for society, the growth in ecotourism should come as no surprise. Pigram (1992), in reviewing research in this area, found that Stankey and McCool's (1985) work suggests that natural settings are of major importance to recreation users: even big game hunting revealed a preoccupation with nature, with two thirds of the hunters interviewed stating that enjoying nature was important (Allen, 1991). Kaplan and Kaplan (1989) report that experiencing nature is a central issue for visitors to natural areas. Studies on recreation motivation by Shafer and Mierz (1969) and Fly (1986) suggests that 'enjoying the natural surroundings' and 'experiencing nature' are the strongest reasons for visiting these environments. Research on white water rafting by Hall and McArthur (1991) reveals that although adventure and excitement are significant motivational factors, the most important motivation cited was the opportunity to experience the natural environment. 
Iso-Ahola (1980) advocates that if we see the environment as self, we are more likely to experience the environment as self. Therefore, by separating humans from the environment we are separating humans from themselves, hence an attraction to natural areas. It is thought that natural areas represents the past. Natural areas in this respect are a living embodiment of the past, contributing to our present sense of duration and identity. For Aboriginal people, this sense of identity is maintained through totemism which accomplishes not only the kinship and co-operation of humans with nature but the continuity between past and present (Levi-Strauss, 1964).

Humans are constantly interacting with their environment, adapting it to suit intrinsically human ends (Proshansky, 1973). Response to the environment is often obtained through feedback from 'others' in relation to the natural environment. In some natural areas however, the environment cannot be changed to suit one's needs. In these cases the human agent must focus on adapting the self rather than the environment. In this way the interaction between the individual and the surrounding environment is founded on a relationship of self-control. That is to say that the behavior modification resulting from the apperception of an unmalleable and often hostile environment is one that fundamentally questions the ontological and existential status of the agent themselves: in short, the very make-up of the value system of the individual is brought into relief.

A process of self control that necessarily shifts the focus inward enhances self consciousness. As this attention shifts from the environment to a physiological state it gravitates to other aspects of the self. This in turn produces a feeling of self reliance resulting in a positive feedback of the self. Slosky (in Scherl, 1988) explains that 
natural areas create a greater awareness of the self, because there is no escape from experiencing the present. The enhancement of these emotional and physical sensations increase an awareness of one's inner capabilities which in turn increases self confidence.It is thought that some people who constantly seek identity images, such as being adventurous, find that a natural area can reinforce identity by allowing the individual a closer understanding of one's individual strengths. Simmel (1965) however, views the excitement derived from the gamble with the forces of nature, in contemporary social systems, as being an excitement not from the gamble itself, but as symptomatic of the modern fetishisation of stimulation. This may be the initial motivating force, but the psychological benefits that result from natural area experience go beyond simply the drive for stimulation. The heightened physiological state occurring when natural environments are used purely for their functional utility, that is, for the stimulation as a physical end in itself, produces a distancing effect by taking one's self away from the self. Natural areas experienced through volunteer tourism however, can facilitate a reconnection with the self through a process of self control resulting in an increase in self confidence, an increased awareness of one's emotional and physiological sensations and enhancing perceived freedom. Self control enhances self feedback, resulting in changing self image.

Now that we are beginning to understand human affinity with nature we can understand why humans look for ecotourism experiences in natural areas. Driver et al (1991; 1996) found there are benefits that are derived from outdoor recreational experiences and that in understanding the physiological and psychological changes that occur, within an individual, through experiencing nature, a range of personal benefits could be seen to result. 
The volunteer tourism experience, when examined in this context seems able to provide the opportunity to learn through experiences (cf. Ewert, 1987; Whitmore, 1988), and the benefits accrued from such experiences can fundamentally influence identity (cf. Scheyer and Driver, 1989), and subsequently affect groups and communities. Thus, while the individual is important in this paper, it is important in understanding ecotourism experiences that the social environment is given significant recognition. Factors that relate to social development include responsibility for others, group co-operation and leadership (Abbott, 1989; Darby, 1994; McRae, 1990).

As leisure and tourism are socially and personally constructed concepts, subject to changes over time and occurrences in differing environments (Hamilton-Smith, 1992; Kaplan, 1975), they are perhaps best defined 'by those engaging in it' (Stebbins, 1982: 254). Wearing (1998b) finds that the volunteer tourism experience incorporates the idea that:

- the experience is a personal experience which generally incorporates the perception that it is chosen for its difference and involves intrinsic motivation;

- it can potentially benefit the person's life and the host community; and

- meaning is given to the experience through social interaction which may involve a re-negotiation of the individual's identity.

It is inherent therefore that the natural features and aesthetic qualities of a volunteer tourism site contribute to this increase in value in a range of ways. The site provides a physical and psychological distancing from the normal 'home' lifestyle with solitude 
and contemplation identified by participants as an important aspect (Wearing, 1999b). Social interaction with the group and community are fundamental elements and contribute to the social exchange (seen as a process) of the experience. The site also provides a range of other opportunities that allow social-interaction-as-leisure as a component of the socio-cultural exchange, contributing to the attitudinal shift in the way the volunteer tourist feels about themselves, their lifestyle, and the way in which they regard the social and natural environment. All of these factors contribute to the valuation of the site; this valuation in relation to natural environments in general has been attenuated demonstrably as a result of the process of the experience.

The operation of social interaction in this aspect of the tourism experience emphasises the connection between Wearing's (1998b) data and related studies of outdoor recreation behaviour which find that social groups and the family stage are important determinants of outdoor recreation participation (Manning, 1986: 16; Roggenbuck and Lucas, 1987: 204). This illustrates the development of a common meaning for the volunteer tourism sites as settings that accommodate the variety of leisure needs of the volunteer tourist, while allowing for the similarities and differences which may be determined by common family and social backgrounds.

Social processes contribute significantly to the development of meanings about the volunteer/ecotourism experience. These meanings are derived through social interaction with family and friends and reflect Stryker's observations about the development of meanings as they affect behaviour: 
"[in the symbolic interactionist perspective] Behaviour is largely governed by the individual's social definition of the situation, interaction with others in the social milieu, and the self concept [which is] governed to a large extent by others in a social process” (1980: 27).

This reinforces the utility of the interactionist perspective in understanding the observed patterns of behaviour. It recognises the status and significance of others in a social group as a dominant construct, as opposed to research based in psychology and social psychology, which regards the influence of others as peripheral in relation to individual decision making.A theoretical interpretation of these observations suggests that macro-social phenomena, such as an ideology of environmentalism ${ }^{6}$ as it influences individual roles in wider society, is variable in micro-social contexts such as the volunteer/ecotourism experience ( $c f$. Clarke et al. 1975). According to Foucault (1981), social institutions (such as the family) constitute and govern individuals through hegemonic discourses (such as those surrounding environmentalism). In the future, an understanding of the discourse of environmentalism may assist in understanding the ecotourism experience particularly as expressed by the volunteer tourist here. For these participants the discourse of environmentalism creates a belief of what can be achieved in volunteer tourism projects.

The styles of interaction apparent here involve intimate relationships with the group, sociable contact with representatives of the community and elements of the natural environment. There was a clear expectation of this interaction as a component of the 
volunteer/ecotourist experience with social interaction identified as an important aspect of the experience among the volunteers interviewed. Meaning will be constructed according to individual volunteer tourists’ cultural and social backgrounds but it appears that the individual/group interaction in the inter-relational nexus between the elements of the experience fundamentally impacts upon participant's sense of self and identity.

\section{The self/other connection and volunteer tourism}

"I think the biggest impact was what I was talking about earlier, and the way that the experience affected me. I think my tolerance level and my acceptance levels aren't as black and white any more. It doesn't necessarily have to be about environmental things, just generally. You may not agree with the way someone lives or someone else's value system, but you've got no right to sit there and judge it, or try and change it unless you really see some benefit in re-educating people to another way of thinking. It doesn't matter that they have a totally different system to the way we do things, just enjoy the differences" (Amyvolunteer tourist), (Wearing 1998b: 210).

Different ideas abound of what constitutes the 'self' of a volunteer tourist; but there are certain generally accepted specifications:

\section{( . . continued)}

${ }^{6}$ For an outline of the roots of modern environmentalism see Pepper (1984) 'The Roots of Modern Environmentalism': for its relationship to society see Eckersley (1992) 'Environmentalism and Political Theory’: for its effects on individual identity see Fox (1990) ‘Towards a Transpersonal Ecology’. 
'It is necessary to make my name known; I must have power - physical, social, intellectual, artistic, political.... but power. I must leave monuments, I must be remembered. I must be admired, envied, hated, feared, desired. In short, I must endure, I must extend, and beyond the body and the body's life' (Fowles 1968: 9).

The volunteer tourist needs all of the above, then to incorporate the other of nature into self. Nature is used here as an example of the self/other connection through volunteer tourism as it provides a specific focus. The elimination of ethics, human freedom, religion and spirituality from the Western world view - the very elements of our experience which empowers us as human beings - has been one of the great contributions to deeply ingraining a sense of powerlessness into the way we think about ourselves and nature. Our sense of nothingness consumes our psyche, and in turn we consume the earth beyond matters of survival (Brennan 1996). The volunteer tourist often seeks to move beyond this through volunteering, as the quotes below illustrate.

\begin{tabular}{|l|l|}
\hline “That was the trigger which made me & “...doing something constructive or \\
think I would like to do something of a & helpful, rather than just going and \\
worthwhile nature and I think the cause & looking” (Mic). \\
is good” (Jen). & “...doing community development and \\
“...do something that was worthwhile” & volunteer work. I' d always thought about \\
\hline
\end{tabular}




\begin{tabular}{|l|l|}
\hline (Ann). & doing volunteer work” (Sue). \\
“...to do something for another country” & “...working with them and trying to \\
(Meg). & improve their lives” (Kim). \\
“...going to a foreign country and doing & \\
volunteer work” (Pen). & \\
\hline
\end{tabular}

(Wearing 1998b: 140)

The egalitarian philosophy of ecocentrism, as imbibed in ecotourism, combined with the evolution of interactionism allow us in a poststructural sense to explore the inclusion of nature into the self through travel previously unexplainable because of the limited application of theory. If the volunteer tourist then takes on the ecocentrism of "othered" nature, we find support for the notion that this type of experience - when theorised - offers a way forward for the development of theory.

“I think most people would be lying if they didn’t say there was some selfishness in why they were going. Because it was really to benefit themselves, not just the environment and community in Santa Elena, even though it is really important. And that's one of the things I had trouble with at first. I thought that it was really selfish on my part, because I just wanted to go over and see what Costa Rica was like. Helping save a pristine rainforest in Santa Elena as well as help the community in developing their ecotourism, which is helping save the rainforest ultimately - they were secondary things. But when you come back, you think 
how you benefited a lot out of it and it was really great. When you look at the whole picture, you think well maybe we have affected this community and have possibly saved a cloudforest” (Ken - volunteer tourist), (Wearing 1998b: 143).

Thus if we examine the volunteer tourism experience as a process, involving components of learning about nature then it would be reasonable to suggest — and many of the volunteer tourist respondents' statements (Wearing 1998a) have suggested as much — that the experience itself is likely to impact on the formation of participants' values and therefore their sense of identity. If it is shown that the volunteer tourism experience affects the values and identity of the volunteer in relation in this case to nature, then certain ideas can be developed. For example, it would therefore suggest that this constitutes a fundamental nodal point in identity formation and construction; crucially, one which is inherently constructed around the notion of value for a physical place, that is a site of constellations of values and meanings that are negotiated, constructed and mediated upon, where the identities of individuals can be constructed, developed, rejected and/or refined. Conceptualised in this way, such an approach attempts to provide a theorisation of how volunteer tourism can influence value systems and identity formation. It is then considered imminently possible that if such experiences can be provided, allowing individuals to challenge and resist dominant identarian models, cultural stereotypes and perception and construction of nature/environment itself, then the opportunity arises for a concomitant range of alternative identities and value systems that may be encountered and explored by individuals. 
Ittleson et. al. (1974: 5) maintain that the individual is not a passive product of their environment, but interacts with their environment and is in turn influenced by it. Interactionism suggests that the individual is an active, thinking unit who is able to construct a meaningful existence and a sense of self from the social milieu in which she/he lives:

“The individual expresses himself [sic] as such, not directly, but only indirectly, from the particular standpoints of other individual members of the same social group or from the generalised standpoint of the social group as a whole” (Mead 1934: 138).

The volunteer tourism experience is constructed via a process that enables an investigation of the 'social self' (cf. Kellehear 1996). This process is in exchange with the destination environment: the host community and the natural environment. In this experience the social interaction between the volunteer tourist, the host community and natural environment form an exchange of influence that creates a social value of the site for the volunteer tourist that effects a change in self and identity. As such, the behaviour and values of the volunteer tourist have been impacted upon, and they come away from the experience with a changed value for the social and physical environments visited.

\section{Postcolonial theorists, self and travel}


When poststructuralist theory is applied to leisure and the self/other binary opposition is deconstructed it becomes clear that concern for others, understanding of others and care of others can impinge on the self in a positive way. If this is used to reanalyse the self/other/nature continuum we are able to move on from the idea of congratulating ourselves on saving nature to the development of ideas of the self that see nature as a part of being. This application may be used for a range of nature-based activities that bring an interaction with nature.

Interactionist theory has long recognised the interplay of the self with its emphasis on the contribution that 'significant others' and 'significant reference groups' make to one's sense of self. Yet in both interactionist and environmentalist theory, 'self' is prioritized over 'other' and there is a clear demarcation between the two: self being seen as the subject and the other as the object. If, through postcolonialist theory the binary opposition of 'self' and 'other' is deconstructed so that 'self' is no longer prioritised over 'other', and furthermore ecocentrism is able to be included into our concept of nature, the idea of travel can move to a circumstance where the commodified, individualised and self-centred focus is progressed. This allows nature to take on different meaning in which involvement with the other is a part of travel in nature and not separate from it.

If we include postcolonialist theory into our ideas of travel as it relates to ecotourism as Wearing (1998a) has for leisure, it enables a '....a radical rethinking of forms of knowledge and social identities authored and authorised by colonialism and Western domination’ (Prakash, 1994:87). Tourism theory has been particularly concerned with 
the lived experiences of western middle-class white males who have taken on the traditions mentioned earlier that subjugate nature. Collins notes that in the Black community, self is not defined in opposition to others, rather, 'the connectedness among individuals provides Black women deeper, more meaningful definitions' (1990:106). For these communities 'self' cannot mean the extreme individualism of Western thinking, but is inherently related to others in the family and community (Wearing 1998a).

Postcolonial theorists (cf. hooks 1989, Spivak 1988a; 1988b; Collins 1990) allow us to let nature enter the dialogue with a voice. This, reinforced with an ecocentric view of nature, brings together the self/nature split and in the deconstruction of this dichotomy there is also a critique of the extreme emphasis that has been placed on the expression and development of the individual self in Western cultures. Travel allows us to expand our views both theoretically and experientially. In this view the idea of self-enhancement without the enhancement of nature would be alienating. The 'I' that is very much one that incorporates the 'we' of the natural environment. Nature as a volunteer's travelled experience can go beyond their own family, community or cultures' view of it to take on new, more inclusive meanings.

\section{Conclusion}

This paper has considered and integration of interactionist/environmentalist and post colonialist theory in an attempt to move towards an explanation of volunteer tourism as a form and means of integrating ideas of the self and other. The example of the 
integration of nature has been sued to illustrate this theorisation. In this new view the further the volunteer traveller ventures into the unknown elements of the "other", the greater awareness they will have of the integral part nature plays in their travel and as a result the increase their scope for self-realisation in their identify.

Insights from poststructuralist and postcolonialist theory add another dimension to theorising tourism travel and allow a more thorough analysis of the volunteer tourism experience. For in this analysis we involve a critique of the self/other dichotomy where self has been valued over the other. The dialogue the volunteer has with other cultures' views of nature through their often elongated and more intense travel experience provides us a different perspective, and decentres the excessive focus on the self which has been at the core of tourism analysis.

"Personally, in the sense of that we were doing something constructive and productive and it was actually ... a community project and the benefits were being felt in the community. It gave me a sense that what we were doing was something that was on the right tracks. .......It broadened my ideas of what people were like and that no matter what country you are in, you all face the same kind of problems to different degrees. I think it is a chance to put your own culture into perspective too” (Ros - volunteer tourist), (Wearing 1998b: 221).

When the "other" assumes as much importance in the conceptualisation of ideas surrounding ecotourism leisure as the "self”, views of tourism can be pushed beyond the boundaries of merely focussing on self-determination, self-improvement, selfenhancement and self-choice. This is not, however, to eliminate the idea of self and 
travel but allows an extension of the way travel is conceptualised and a more inclusive role for specialist areas such as volunteer tourism. It allows us to decommodify our views of tourism and move it towards a more appropriate analysis.

"It [the volunteer tourism experience] made me a lot more critical of a consumer's society. I think there are a lot of things here that are all very nice and convenient and are good for status. But there are a lot of things we just don't need. If something is broken, we go down the shop and buy another one, or buy a dishwasher instead of doing it yourself. I have become more critical of my environment, because each time I buy something, I have to really justify to myself, do I need this or is it just something to do with the money I'm spending my life earning. A lot of people have an identity, their car or their job is their identity. So when you meet them, in the first couple of minutes, they're telling you, 'I do this' or 'I have this'. It shrinks your identity, but I'm not sure if it shrinks it, as much as it defines it. It takes away all the things that aren't you and leaves you with just the core, so it is really just chopping away at the unnecessary bits." (Ros - volunteer tourist), (Wearing 1998b: 242).

The scenario of nature developed here provides us with one avenue of exploration that can demonstrate how volunteer tourism may see a re-integration of nature into society in a decommodified form. Furthermore, its value and the future based on a deconstruction of the self/other dichotomy may see it incorporated into an ethic of travel. 
****** $*$

Note: The authors wish to thank Mark Jackson for editorial on the final draft. 


\section{References}

Abbott, C. (1989). The wilderness experience as personal development - why it works and how to enhance it; lessons from a drug rehabilitation program. In B. Hayllar (ed.) 6th National Outdoor Education Conference Proceedings. Sydney: University of Technology, Sydney.

Allen, L.R. (1991). Benefits of leisure services to community satisfaction. In B.L Driver, J. Brown, and L. Peterson (eds) Benefits of Leisure. State College, Pennsylvania: Venture.

Berger, P. and Luckmann, T. (1981). The social construction of reality. London: Penguin.

Boo, E. (1990). Ecotourism: The potentials and pitfalls. Washington D.C: World Wide Fund For Nature.

Bookchin, M (1982). The ecology of freedom: The emergence and dissolution of hierarchy. California: Palo Alto Publishing.

Bramwell, B. and Rawding, L. (1996). Tourism marketing images of industrial cities, Annals of Tourism Research, 23, 201-221. 
Brennan, A. (1996). Ethics, ecology and economics. In N.S Cooper and R.C.J Carling (eds) Ecologists and Ethical Judgements. London: Chapman and Hall Ltd.

Brown, G. (1992). Tourism and symbolic consumption. In P. Johnson and B. Thomas (eds) Choice and demand in tourism. Mansel: London.

Butler, J (1993). Bodies that matter. London: Routledge.

Butler, J.R. (1992). Ecotourism: Its changing face and evolving philosophy. Paper presented at the International Union for Conservation of Nature and Natural Resources (IUCN), IVth World Congress on National Parks and Protected Areas, Caracas, Venezuela, February 10-12.

Ceballos-Lascurain, H. (n.d.). (unpub.). Faxed research notes from the author in 1987.

Clarke, J. and Critcher, C. (1985). Leisure in capitalist Britain: The devil makes work. London: MacMillan.

Clarke, J., Hall, S., Jefferson, T. and Roberts, B. (1975). Subcultures, cultures and class. In S. Hall and T. Jefferson (eds) Resistance Through Rituals. London: Hutchinson.

Cohen, E. (1995). Contemporary tourism - trends and challenges: Sustainable authenticity or contrived post-modernity? In R. W. Butler and D. Pearce (eds) Change in tourism: People, places and processes. London: Routledge. 
Cohen, C.B. (1995). Marketing paradise, making nation, Annals of Tourism Research, 22, 404-421.

Cohen, E. (1988). Authenticity and commoditization in tourism, Annals of Tourism Research 15, 371-386.

Cohen, E. (1987). Alternative tourism-a critique, Tourism Recreation Research 12 (2), 13-18.

Cohen, S. and Taylor, L. (1976). Escape attempts. Harmondsworth: Penguin.

Collins, P.H. (1990). Black feminist thought: Knowledge, consciousness and the politics of empowerment. New York: Unwin Hyman.

Craib, I. (1998). Experiencing Identity. London: Sage.

Dann, G. (1995). A socio-linguistic approach towards changing tourist imagery. In R. Butler and D. Pearce (eds) Change in tourism: People, places, processes. London: Routledge.

Darby, M. (1994). International development and youth challenge: Personal development through a volunteer experience. MA (Leisure Studies) Thesis, School of Leisure and Tourism Studies, University of Technology, Sydney. 
Devall, B (1988). Simple in means, rich in ends - practicing deep ecology. Layton, USA: Gibbs Smith Publisher.

Dilley, R.S. (1986). Tourist brochures and tourist images, Canadian Geographer, 30, 59-65.

Driver, B. L., Dustin D., Baltic, T., Elsner, G. and Peterson, G.L. (1996). Nature and the human spirit: Toward an expanded land management ethic. State College, Pennsylvania: Venture.

Eckersley, R. (1992). Environmentalism and political theory - Towards an ecocentric approach. Albany: State University of New York Press.

Echtner, C.M. and Ritchie, J.R. (1991). The meaning and measurement of destination image, Journal of Tourism Studies 2, 2-12.

Ewert, A.W. (1987). Research in Experiential Education. Journal for Experiential Education 10 (2), Summer, 4-7.

Fly, J. (1986). (unpub.). Nature, outdoor recreation and tourism: The basis for regional population growth in northern lower Michigan. $\mathrm{PhD}$ thesis, University of Michigan, Michigan.

Foucault, M. (1981). The History of Sexuality, Vol 1, $2^{\text {nd }}$ edn. Harmondsworth: Penguin. 
Foucault, M. (1983). The subject and power. In H. Dreyfus and G. Rabinow (eds) Michael Foucault: Beyond structuralism and hermeneutics. Chicago: Chicago University Press.

Fox, W. (1990). Towards a transpersonal ecology. Boston: Shambhala.

Game, A. (1991). Undoing the social: Towards a deconstructive sociology. Milton Keynes: Open University Press.

Gartner, W. (1993). Image formation process, Journal of Travel and Tourism Marketing, 2, 191-215.

Godfrey-Smith, W. (1980) The value of wilderness: a philosophical approach. In R.W. Robertson, P. Helman and A Davey (eds) Wilderness management in Australia: Proceedings of a symposium at the Canberra College of Advanced Education $19^{\text {th }}-23^{\text {rd }}$ July (pp. 56-71). Canberra: Canberra College of Advanced Education.

Goffman, E. (1974). Frame analysis: An essay on the organisation of experience. Cambridge, Mass: Harvard University Press.

Grosz, E (1989). Sexual subversions. Sydney: Allen and Unwin.

Grosz, E (1994). Volatile bodies. Sydney: Allen and Unwin. 
Hall, C.M. and McArthur, S. (1991). Commercial white water rafting in Australia. Leisure Options 1 (2), 15-21.

Hamilton-Smith, E. (1992). Work, leisure and optimal experience. Leisure Studies 11, 243-256.

Hardin, G. (1968). The tragedy of the commons. Science, 162.

Holden, P. (ed.) (1984). Alternative tourism: Report on the workshop on alternative tourism with a focus on Asia. Bangkok: Ecumenical Coalition on Third World Tourism.

Holland, A. (1996). The use and abuse of ecological concepts in environmental ethics. In N.S Cooper and R.C.J Carling (eds) Ecologists and ethical judgements. London: Chapman and Hall Ltd.

Hollinshead, K. (2000) Bhabha and the fantasmatics of the restless, contemporary world: the translation of Bhabhian thought on hybridity and enunciation to the transdisciplinary realms of tourism studies. Paper presented at The travelling concepts: text, subjectivity, hybridity conference January 2000, Amsterdam.

Hollinshead, K. (1999a) Surveillance of the worlds of tourism: Foucault and the eye-ofpower, Tourism Management, 20, 7-23. 
Hollinshead, K. (1999b) Tourism as public culture: Horne’s ideological commentary on the Legerdemain of tourism, International Journal of Tourism Research, 1, 267292.

hooks, B (1993). 'Eros, eroticism and the pedogogical process' in Cultural Studies 7, No.1, January.

hooks, B. (1989). Feminist theory: From margin to centre. Boston, MA: South End Press.

Hummel, D. (1987) Stealing The National Parks. Bellevue: Free Enterprise Press.

Ittelsen, W.H., Proshansky, H.M. and Rivilin, L.G. (1974). An introduction to environmental psychology. New York: Holt, Rinehart and Winston.

Irigaray, L (1993). An ethics of sexual difference. Transl. C.Burke and G.Gill, New York: Ithaca.

Iso-Ahola, S. E. (1980). The social psychology of leisure and recreation. Iowa: Wm. C. Brown.

Jagtenberg, T. and Mckie, D. (1997). Eco-impacts and the greening of postmodernity: New maps for communication studies, cultural studies, and sociology. Thousand Oaks, California: Sage. 
Kaplan, M. (1975). Leisure: Theory and Policy. Springfield, Illinois: Thomas.

Kaplan, R. and Kaplan, S. (1989). The experience of nature: A psychological perspective. Cambridge: Cambridge University Press.

Kellehear, A. (1996). Social Self, Global Culture: A Personal Introduction to Sociological Ideas. In ed. A. Kellehear (ed.) Social Self, Global Culture: An Introduction to Sociological Ideas. Melbourne: Oxford University Press.

Kelly, J. (1983). Leisure identities and interactions. London: Allen and Unwin.

Leopold, A. (1949). A Sand Country Almanac. London: Oxford University Press.

Levi-Strauss, C. (1964). Totemism. London: Merlin Press.

Livingston, J.A. (1991). The fallacy of wildlife conservation. Ontario: McCelland and Stewart.

Lloyd, G. (1989). Woman as other: sex, gender and subjectivity, Australian Feminist Studies 10:13-22.

Lynch, R. and Veal, A.J. (1996). Australian Leisure. Melbourne: Longman.

MacCannell, D. (1992). Empty meeting grounds: The tourist papers, London: Routledge. 
Manning, R. E. (1986). Studies in outdoor recreation: A review and synthesis of the social science literature in outdoor education. Corvalis, Oregon: Oregon State University Press.

Mead, G.H. (1934, 1972). Mind, Self, Society. Chicago: University of Chicago Press.

McRae, K. (ed.). (1990). Outdoor and environmental education. Melbourne: Macmillan.

Nash, R.F (1989). The rights of nature - A history of environmental ethics. Madison, Wisconsin: The University of Wisconsin Press Ltd.

Pepper, D. (1984). The roots of modern environmentalism. Croom Helm: London.

Pigram J.J. (1992). (unpub.). Human-nature relationships: Leisure environments and natural settings. University of New England, Armidale.

Prakash, G. (1994). Postcolonial criticism and Indian historiography, in L. Nicholson and S. Seidman (eds) Social Postmodernism: Beyond Identity Politics. Cambridge, UK: Cambridge University Press, 87-100.

Proshansky, H.M. (1973). The environmental crisis in human dignity. Journal of Social Issues 29 (4), 12-22. 
Richter, L.K. (1995). Gender and race: Neglected variables in tourism research. In R. Butler and D. Pearce (eds) Change in tourism: people, places, processes. London: Routledge.

Roberts, K. (1983). Youth and leisure. London: Allen and Unwin.

Roggenbuck, J. W. and Lucas, R. C. (1987). Wilderness use and user characteristics: A state of knowledge review. Missoula, Montana: United States Forest Service.

Rojek, C. (1985). Capitalism and leisure theory. London: Tavistock.

Rojek, C. (1993). Ways of escape: Modern transformations in leisure and travel. London: Macmillan.

Rojek, C. (1998). Leisure theory: Retrospect and prospect. Society and Leisure 20 (2) 383-400.

Rolston III, H. (1992). Challenges in environmental ethics. In D.Cooper and J.Palmer (eds) The Environment in question. London: Routledge.

Rowe, D. and Stevenson, D. (1994). Provincial paradise: Urban tourism and city imaging outside the metropolis. The Australian and New Zealand Journal of Sociology, 30, 178-193. 
Scherl, L.M. (1988). The wilderness experience: Psychological and motivational considerations of a structured experience in a wilderness setting. $\mathrm{PhD}$ thesis, James Cook University of North Queensland, Townsville, Australia.

Shafer, E and Mietz, J. (1969). Aesthetic and emotional experiences rate high with northeast wilderness hikers. Environment and Behaviour 1, 187-197.

Scheyer, R. and Driver, B.L. (1989). The benefits of leisure. In J. Jackson and E. Burton (eds) Understanding leisure and recreation: Mapping the past, charting the future.Venture, State College, Pennsylvania, 385 - 420.

Simmel, G. (1965). Essays on sociology, philosophy and aesthetics, 2nd edn. NewYork: Harper and Rowe.

Spivak, G.C. (1988a). Can the subaltern speak? In C. Nelson and L. Grossberg (eds) Marxisms and the Interpretation of Culture. Urbana: University of Illinois Press, 271-313.

Spivak, G.C. (1988b). In other worlds: Essays in cultural politics. New York: Methuen.

Stankey, G. and McCool, S. (eds) (1985). Proceedings - symposium on recreation choice behaviour. United States Forest Service general technical report INT-184. Ogden, USA: United States Department of Agriculture. 
Stebbins, R.A. (1982). Serious leisure: A conceptual statement. Pacific Sociological Review 25 (2), 251-272.

Stryker, S. (1980). Symbolic interactionism: A social structural version. California: Benjamin/Cummings Publications.

Telisman-Kosuta, N. (1989). Tourism destination image. In S.F. Witt and L. Moutinho (eds) Tourism marketing and managing handbook. Prentice Hall: New York.

The International Ecotourism Society (TIES). (2001) Ecotourism Statistical Fact Sheet, 16.1.01. www.ecotourism.org.

Urry, J. (1990). The tourist gaze. London: Sage.

Wearing, S. (2001). Volunteer tourism: experiences that make a difference. London: CABI Publishing (in press).

Wearing, B. (1998a). Leisure and Feminist Theory. London: Sage.

Wearing, S. (1998b). The nature of ecotourism: the place of self, identity and communities as interacting elements of alternative tourism experiences. Unpublished PhD Thesis, School of Environmental and Information Sciences, Charles Sturt University, Albury, Australia. 
Wearing, B.M. and Wearing, S.L. (1988). All in a day's leisure: Gender and the concept of leisure, Leisure Studies, 7, 111-123.

Wearing, B.M. and Wearing S.L. (1996a). Refocussing the tourism experience: The Flaneur and the Choraster, Leisure Studies, 16, 229-243.

Wearing, B. and Wearing, S. (1996b). The Olympic City 2000: Phallic Fallacy in Accessing Leisure Spaces. Paper presented at World Leisure and Recreation Association Congress, Cardiff, UK.

Wearing, B.M. and Wearing S.L. (1992). Identity and the commodification of leisure, Leisure Studies, 11, 3-18.

Wearing S. L. and Wearing B. M. (1999) Conceptualising the selves of tourism. $4^{\text {th }}$ Conference of the Australian and New Zealand Association for Leisure Studies, Leisure Experiences: Interpretation and Action, Department of Leisure Studies, University of Waikato, Hamilton, $29^{\text {th }}$ January $-1^{\text {st }}$ March.

Wearing, B.M.; Wearing, S.L., Kelly, K. (1994). Adolescent women, identity and smoking: leisure experience as resistance. Journal Sociology, Health and Illness. 16 (5) 626-643.

Wearing S. L and Wearing M. (1999). Decommodifying ecotourism: rethinking globallocal interactions with host communities. Loisir and Societe, 22 (1), 39-70. 
Weaver, D. and Opperman, M. (2000). Tourism Management. Milton: John Wiley and Sons.

Whitmore, E. (1988). Adult learning through participation in rural community groups. Journal of Voluntary Action Research 17 (3 and 4), 53 - 69. 


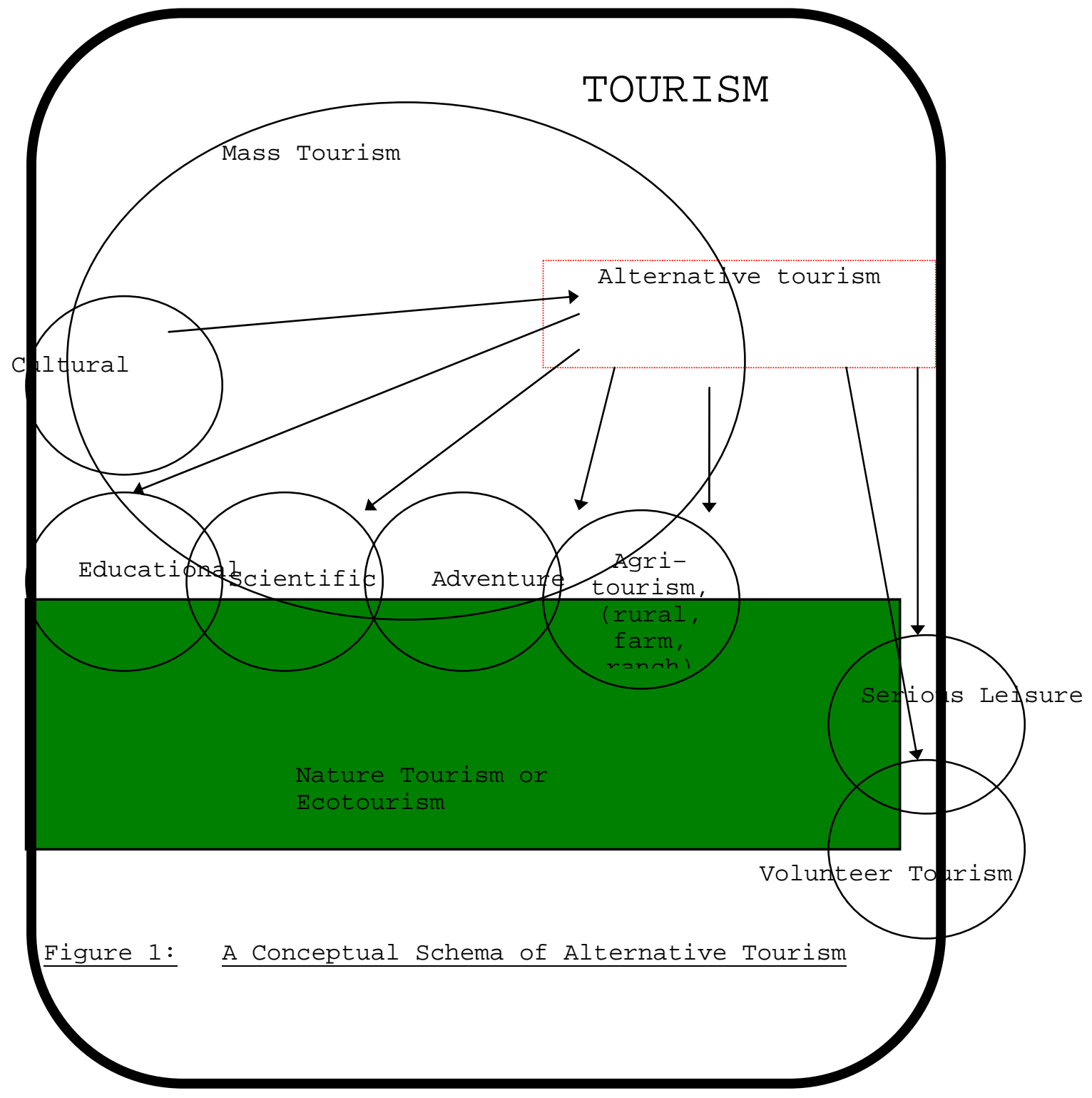

(Wearing, 1998b, 30) 